\title{
Produção e composição bromatológica do capim-Marandu em diferentes épocas de diferimento e utilização
}

\section{Production and chemical composition of Marandu grass in different periods of stockpiled and utilization}

\author{
Conrado Timbó Rodrigues Júnior ${ }^{1}$; Maria Socorro de Souza Carneiro²; \\ João Avelar Magalhães ${ }^{3 *}$; Elzânia Sales Pereira ${ }^{4}$ Braz Henrique Nunes Rodrigues ${ }^{5}$; \\ Newton de Lucena Costa ${ }^{6}$; Maria do Socorro de Caldas Pinto ${ }^{7}$; \\ Alex Carvalho Andrade ${ }^{8}$; Andréa Pereira Pinto ${ }^{9}$; Fabíola Helena dos Santos Fogaça ${ }^{10}$; \\ Karina Neoob de Carvalho Castro ${ }^{3}$
}

\section{Resumo}

\begin{abstract}
O efeito da época de diferimento sobre a produção e composição química da forragem do capim-Marandu (Brachiaria brizantha cv. Marandu), durante a estação seca, foi avaliado em experimento conduzido em Parnaíba, Piauí. O delineamento experimental foi o de blocos casualizados em um esquema fatorial de 3 x 4, sendo três épocas de diferimento ( 23 de março, 19 de abril e 17 de maio) e quatro épocas de utilização (12 de julho, 9 de agosto, 6 de setembro e 4 de outubro) com três repetições. O diferimento em março ou abril, com utilizações em julho a outubro proporciona maiores produções de matéria seca verde, contudo, o diferimento em maio e utilização em julho apresentou melhor relação material vivo/material morto. A forragem com maiores relação folha/colmo, teores de proteína bruta e cinzas, e menores teores de fibra em detergente neutro e fibra em detergente ácido, foram verificadas com utilizações nos meses de julho e agosto, independentemente da época de diferimento. Visando conciliar rendimento e composição química da forragem do capim-Marandu, recomenda-se o diferimento em abril ou maio para utilização em julho ou agosto, respectivamente.

Palavras-chave: Fibra em detergente ácido, fibra em detergente neutro, extrato etéreo, cinzas, proteína bruta
\end{abstract}

\footnotetext{
Abstract

The effect of the stockpiled period on the production and chemical composition of the forage of Marandu grass (Brachiaria brizantha cv. Marandu), during the dry season, was evaluated in an experiment

${ }^{1}$ Eng $^{\circ}$. Agro , M.e, Universidade Federal do Ceará, UFC, Fortaleza, CE. E-mail: conrado.junior@yahoo.com.br

2 Eng $^{\mathrm{o}}$. Agr ${ }^{\mathrm{o}}$, Prof ${ }^{\mathrm{a}} \mathrm{Dr}^{\mathrm{a}}$, UFC, Fortaleza, CE. E-mail: msocorro@ufc.br

${ }_{3}^{3}$ Médicos Veterinários, Drs., Pesquisadores, Empresa Brasileira de Pesquisa Agropecuária/Centro de Pesquisa Agropecuária do Meio-Norte, EMBRAPA/CPAMN, Parnaíba, PI. E-mail: joao.magalhaes@embrapa.br; karina.castro@embrapa.br

${ }^{4}$ Zootecnista, Prof ${ }^{\mathrm{a}} \mathrm{Dr}^{\mathrm{a}}$, UFC, Fortaleza, CE. E-mail. elzania@hotmail.com

5 Eng ${ }^{\circ}$ Agrícola, Dr., Pesquisador da EMBRAPA/CPAMN, Parnaíba, PI. E-mail: braz.rodrigues@embrapa.br

${ }^{6}$ Eng $^{\circ}$ Agr $^{\circ}$, Dr., Pesquisador do Centro de Pesquisa Agroflorestal de Roraima, Embrapa Roraima, Boa Vista, RR. E-mail: newton. lucena-costa@embrapa.br

7 Zootecnista, Prof $^{a}$ Dr $^{\text {a }}$, Universidade Estadual da Paraíba, UEPB, Catolé do Rocha, PB. E-mail: caldaspinto2000@yahoo.com.br

8 Zootecnista, Prof. Dr., Universidade Estadual do Piauí, UESPI, Parnaíba, PI. E-mail: acandrade4@hotmail.com

${ }^{9}$ Médica Veterinária, Prof ${ }^{\mathrm{a}}$ Dr $^{\mathrm{a}}$, UFC, Fortaleza, CE. E-mail: deiapp@ufc.br

${ }^{10}$ Zootecnista, Dra , Pesquisadora da EMBRAPA/CPAMN, Parnaíba, PI. E-mail: fabiola.fogaca@embrapa.br

* Autor para correspondência
} 
conducted in Parnaiba, Piauí. The experimental design was a randomized block design in a factorial $3 \times$ 4, three times stockpiled (March 23, April 19 and May 17) and four utilization times (July 12, August 9, September 6 and October 4) with three replications. The stockpiled in March or April, with pasture utilization in July to October provides greater production of green dry matter, however, the use of stockpiled in May and in July showed better relationship a live material/dead material. The forage with higher leaf/stem ratio, crude protein and ash, and lower levels of neutral detergent fiber and acid detergent fiber were verified with pasture utilization in the months of July and August, regardless of the stockpiled time. Seeking to reconcile yield and chemical composition of the Marandu grass is recommended stockpiled in April or May for pasture use in July or August, respectively.

Key words: Acid detergent fiber, ash, crude protein, ether extract, neutral detergent fiber

\section{Introdução}

As pastagens representam a principal fonte para a alimentação dos rebanhos, as quais na sua maioria são formadas por gramíneas. As áreas pastoris representam 3 bilhões de hectares no mundo, praticamente $20 \%$ da superfície do globo terrestre (GUERRA FILHO, 2012). Neste contexto, o Brasil é um dos países de maior potencial de produção pecuária a pasto, determinada, principalmente, por suas condições climáticas e vasta extensão territorial (SERAFIM; GALBIATTI, 2012). Durante a estação chuvosa, devido a alta disponibilidade e valor nutritivo da forragem, observa-se um desempenho satisfatório dos animais. No entanto, na época seca ocorre o oposto e, como consequência, há perda de peso dos animais ou redução drástica na produção de leite. Esses efeitos são mais acentuados na região Nordeste, onde os índices pluviométricos são irregulares com amplos períodos de seca e má distribuição de chuvas (MAGALHÃES et al., 2012).

Dentre as opções tecnológicas indicadas para minimizar as consequências do período seco e melhorar a produtividade dos sistemas pecuários do Brasil, destacam-se a silagem de milho ou sorgo, feno, capineiras, cana-de-açúcar, adubação e irrigação de pastagens, e diferimento de pastagens (MELLO; NÖRNBERG, ROCHA, 2004; COSTA et al., 2007; BENDAHAN et al., 2009; SANTOS et al., 2009; MAGALHÃES et al., 2012; MOREIRA et al., 2013).
De pouco investimento, o diferimento, também conhecido como vedação ou reserva, consiste em suspender a utilização da pastagem durante parte de seu período vegetativo, de modo a favorecer o acúmulo de forragem para utilização durante a época seca (COSTA; OLIVEIRA, 1992; LEITE; COSTA; GOMES, 1998). Essa tática de manejo é realizada para minimizar os efeitos antagônicos da estacionalidade produtiva das forrageiras tropicais sobre o desempenho animal durante o período seco.

Apesar de apresentar grande quantidade de material morto em função da idade fisiológica da planta (ABREU etal., 2004), a técnica do diferimento de pastagem vem sendo utilizada na Austrália e Estados Unidos há bastante tempo (BURNS; WEDIN, 1964; TAYLOR; TEMPLETON, 1976; LALMAN et al., 2000; NIE; ZOLLINGER, 2012). No Brasil, os resultados de Euclides, Valle e Silva (1990), Canto et al. (2002), Santos et al. (2009) e Costa et al. (2010) indicaram a viabilidade dessa prática. Na região Nordeste ela é pouco utilizada, apesar de suas características climáticas, como a chuva concentrada em apenas quatro ou cinco meses do ano, alta insolação e baixa umidade relativa do ar, serem favoráveis para a reserva de forragens a campo para a estação seca. Euclides et al. (2007) alertam que as plantas forrageiras mais indicadas ao diferimento são aquelas que apresentam baixo acúmulo de colmos e boa retenção de folhas verdes, o que resulta em menores reduções no valor nutritivo ao longo do tempo, como a maioria das gramíneas do gênero Brachiaria. 
O gênero Brachiaria sp. representa aproximadamente $85 \%$ das pastagens cultivadas no Brasil, e destes, 70\% é formada de $B$. brizantha cv. Marandu, conhecida também pelos nomes de brizantão e braquiarão (SANTOS FILHO, 1996; SCHUNKE, 2001; FRANÇA, 2005; HEINRICHS et al., 2012). Essa gramínea apresenta produtividade elevada, bom valor nutritivo e persistência em períodos de estiagem, além de boa adaptação à maioria dos solos tropicais. Vegeta bem em altitudes que variam desde o nível do mar até 1.500 $\mathrm{m}$, principalmente em regiões com precipitação pluviométrica entre 1.000 e $2.500 \mathrm{~mm} /$ ano, embora produza em locais com precipitações próximas a 700 mm (COSTA, 2001, OLIVEIRA; MACHADO; POSO, 2006).

Alterações sazonais nas condições ambientais promovem variações na produção e na composição da forragem. Segundo Gerdes et al. (2000), as produções de matéria seca do capim-Marandu aos 35 dias, em corte único em cada estação do ano variaram entre 3,76 $t /$ ha na primavera, 2,03 $t /$ ha no verão, 1,19 t/ha no outono e $0,95 \mathrm{t} /$ ha no inverno. Botrel, Alvim e Xavier (1999) reportaram que essa gramínea produziu 16,27 t/ha/ano de MS, sendo $13,09 \mathrm{t} / \mathrm{ha}$ durante o período chuvoso, e 3,28 t/ha no período de seca, que correspondeu a $20 \%$ da produção total. Já Ribeiro et al. (2008) encontraram em plantas de capim-Marandu, 22,8 e $57,7 \%$ de teores de matéria seca, 9,4 e 4,5\% de proteína bruta, 6,9 e $6,4 \%$ de cinzas, 68,4 e $75,7 \%$ de fibra em detergente neutro e 42,1 e $49,8 \%$ de fibra em detergente ácido, respectivamente, nos períodos de verão e inverno.

Com este estudo, objetivou-se avaliar, nas condições edafoclimáticas dos tabuleiros costeiros do Piauí, a produção e a composição químicobromatológica do capim Brachiaria brizantha cv. Marandu, submetido a diferentes épocas de vedação para uso no período seco.

\section{Material e Métodos}

O ensaio foi conduzido no período de março a outubro de 2011, na Unidade de Execução de Pesquisa de Parnaíba, pertencente à Embrapa MeioNorte, localizada no município de Parnaíba, PI. O clima da região, segundo Koopen, é Aw, com estação seca bem definida (julho a dezembro) e pluviosidade média anual de $1.300 \mathrm{~mm}$. Durante o ano de 2011 o volume de chuva foi de $1.068 \mathrm{~mm}$. Contudo, durante o período experimental a precipitação pluvial ocorreu de forma irregular, distribuída da seguinte forma: fevereiro (255,2 mm), março (168,3 mm), abril (347,2 $\mathrm{mm})$, maio $(74,5 \mathrm{~mm})$, junho $(63,7 \mathrm{~mm})$, julho $(60,9$ $\mathrm{mm})$; agosto $(5,3 \mathrm{~mm})$, setembro $(0,0 \mathrm{~mm})$ e outubro $(0,0 \mathrm{~mm})$. Historicamente, a média das temperaturas máximas e mínimas da região é de $36{ }^{\circ} \mathrm{C}$ e $22{ }^{\circ} \mathrm{C}$, respectivamente. No decorrer do experimento, foi registrada temperatura mínima de $20,0{ }^{\circ} \mathrm{C}$, média de $28,6^{\circ} \mathrm{C}$ e máxima de $37,3{ }^{\circ} \mathrm{C}$.

O solo da área experimental é da classe Latossolo Amarelo distrófico, de textura média, fase caatinga litorânea e relevo plano e suave ondulado (MELO et al., 2004). No início do experimento o solo apresentou as seguintes características químicas: $\mathrm{MO}=4,92 \mathrm{~g} / \mathrm{kg} ; \mathrm{pH}\left(\mathrm{H}_{2} \mathrm{O} 1: 25\right)=6,19 ; \mathrm{V}=47 \%$; $\mathrm{m}=0,0 \% ; \mathrm{P}=4,40 \mathrm{mg} / \mathrm{dm}^{3} ; \mathrm{K}, \mathrm{Ca}, \mathrm{Mg}, \mathrm{Na}, \mathrm{Al}$, $\mathrm{H}+\mathrm{Al}$, S e CTC $=0,09 ; 0,95 ; 0,53 ; 0,01 ; 0,00 ; 1,78$; 1,$58 ; 3,36 \mathrm{cmol}_{\mathrm{c}} / \mathrm{dm}^{3}$, respectivamente.

A gramínea foi estabelecida no início do período chuvoso de 2008, aplicando-se o equivalente a 70 $\mathrm{kg} /$ ha de $\mathrm{P}_{2} \mathrm{O}_{5}$. Um mês após o plantio procedeuse a adubação de cobertura com $60 \mathrm{~kg} / \mathrm{ha}$ de $\mathrm{K}_{2} \mathrm{O}$ e $100 \mathrm{~kg} / \mathrm{ha}$ de N. A área foi utilizada por bovinos até dezembro de 2010. Em fevereiro de 2011 foi implantado este experimento, cujo delineamento experimental foi o de blocos casualizados em um esquema fatorial de $3 \times 4$, sendo três épocas de diferimento (23 de março, 19 de abril e 17 de maio) e quatro épocas de utilização (12 de julho, 9 de agosto, 6 de setembro e 4 de outubro), com três repetições. 
O corte de uniformização foi realizado a 20,0 $\mathrm{cm}$ acima do solo, com roçadeira motorizada e posteriormente, procedeu-se à aplicação do equivalente a $50 \mathrm{~kg} / \mathrm{ha}$ de $\mathrm{N}$ na forma de ureia. As parcelas mediam $7,5 \mathrm{~m}^{2}$ com espaçamento entre parcelas de $0,5 \mathrm{~m}$, sendo a área útil da subparcela de $1,0 \mathrm{~m}^{2}$. A adubação de estabelecimento constou da aplicação de $50 \mathrm{~kg}$ de $\mathrm{P}_{2} \mathrm{O}_{5} /$ ha, sob a forma de superfosfato triplo.

Os cortes foram realizados a uma altura de 20,0 cm do solo nas datas determinadas pelos tratamentos. Após cada corte, foram obtidas amostras que, depois de separadas em folha (lâmina foliar), colmo (colmo+bainha) e material morto, foram pesadas em balança eletrônica e submetidas à pré-secagem em estufa com circulação forçada de ar, a $65^{\circ} \mathrm{C}$ por 72 horas, para estimativa da produtividade de massa seca verde, relação material vivo/material morto e relação folha/colmo. Posteriormente, no Laboratório de Nutrição Animal da Universidade Federal do Ceará (UFC), foram determinados da folha e colmo os teores de proteína bruta (PB), pelo método de Kjeldahl, cinzas (matéria mineral), extrato etéreo, fibra em detergente neutro (FDN) e fibra em detergente ácido (FDA), de acordo com a metodologia preconizada por Silva e Queiroz (2002). A digestão para obtenção da FDN e FDA foi realizada em aparelho de digestão de fibra (modelo Tecnal TE-149, similar ao Ankon) (BERCHIELLI et al., 2001). As amostras foram colocadas em saquinhos de tecido de TNT $100 \mathrm{~mm}$, com tamanho de $25 \mathrm{~cm}^{2}$, selados, sendo que em cada um foi depositado 0,5 g de massa pré-seca moída em peneira de $1 \mathrm{~mm}$.

As análises estatísticas foram realizadas através do programa computacional Assistat (SILVA e AZEVEDO, 2002) e para comparação de médias foi utilizado o teste Tukey ao nível de $5 \%$ de probabilidade.

\section{Resultados e Discussão}

A produtividade de matéria seca verde da Brachiaria brizantha (capim-Marandu) foi afetada $(\mathrm{P}<0,05)$ apenas pela época de diferimento. Independentemente das épocas de utilização, o diferimento em maio $(6,11 \mathrm{t} / \mathrm{ha})$ resultou em rendimentos de matéria seca verde inferior $(\mathrm{P}<0,05)$ ao verificado em março $(9,74 \mathrm{t} / \mathrm{ha})$ ou abril $(8,76 \mathrm{t} /$ ha) (Tabela 1). Esta situação já era esperada, pois as plantas que foram diferidas em março e abril permaneceram por mais tempo em crescimento, beneficiando-se das condições favoráveis do ambiente.

Tabela 1. Produtividade de matéria seca verde (t/ha) de Brachiaria brizantha cv. Marandu, em função das épocas de diferimento e utilização, nas condições edafoclimáticas de Parnaíba, Piauí (2011).

\begin{tabular}{ccccccc}
\hline \multirow{2}{*}{ Épocas de diferimento } & \multicolumn{9}{c}{ Épocas de utilização } & \multirow{2}{*}{ Médias } & \multirow{2}{*}{ CV* (\%) } \\
\cline { 2 - 5 } & Julho & Agosto & Setembro & Outubro & & \\
\hline Março & 10,24 & 11,99 & 7,44 & 9,27 & $9,74^{\text {a }}$ & \\
Abril & 10,67 & 7,75 & 8,48 & 8,14 & $8,76^{\text {a }}$ & 8,80 \\
Maio & 5,79 & 5,49 & 5,97 & 7,18 & $6,11^{\text {b }}$ & \\
\hline Médias & 8,90 & 8,41 & 7,30 & 8,20 & \\
CV* (\%) & \multicolumn{7}{c}{22,41} \\
\hline
\end{tabular}

* = Coeficiente de variação.

- Na coluna, médias seguidas de mesma letra, não diferem entre si $(\mathrm{P}>0,05)$ pelo teste de Tukey.

Fonte: Elaboração dos autores. 
Em Capitão Enéas, Minas Gerais, região com precipitações pluviométricas entre 700 e 1.200 $\mathrm{mm}$, Gomes (2003) observou que, isoladamente, quando o capim-Marandu foi diferido no mês de janeiro, apresentou produtividade de matéria seca verde superior às demais vedações (fevereiro, março e abril), resultante das condições de temperatura, pluviosidade do período de avaliação, além do maior período de vedação. Fato também observado por Barbosa, Monks e Centeno (1995) em capim-elefante (Pennisetum Purpureum). Costa et al. (2010), em trabalho realizado em Porto Velho, Rondônia, constataram que pastagens de Brachiaria brizantha cv. Xaráes diferidas nos meses de janeiro e fevereiro proporcionavam maiores rendimentos de forragem quando utilizadas em agosto e setembro.

Não houve interação entre tratamentos para relação material vivo/material morto $(\mathrm{P}>0,05)$, no entanto, a análise de variância indicou efeito isolado $(\mathrm{P}<0,05)$ das épocas de diferimento e épocas de utilização (Tabela 2). Desta forma, o diferimento em maio e a utilização em julho, apresentaram a maior relação MV/MM. Isto pode ter ocorrido pelo fato de maio ser o último mês de vedação e julho ser o primeiro mês de utilização, logo a pastagem teve menos tempo de crescimento, comparativamente aos demais períodos de diferimento.

Tabela 2. Relação material vivo/material morto de Brachiaria brizantha cv. Marandu, em função das épocas de diferimento e utilização nas condições edafoclimáticas de Parnaíba, Piauí (2011).

\begin{tabular}{|c|c|c|c|c|c|c|}
\hline \multirow{2}{*}{ Épocas de diferimento } & \multicolumn{4}{|c|}{ Épocas de utilização } & \multirow{2}{*}{ Médias } & \multirow{2}{*}{$\mathrm{CV}^{*}(\%)$} \\
\hline & Julho & Agosto & Setembro & Outubro & & \\
\hline Março & 3,77 & 3,16 & 2,67 & 2,97 & $3,15^{b}$ & \\
\hline Abril & 5,88 & 2,59 & 2,84 & 2,74 & $3,51^{\mathrm{b}}$ & 38,38 \\
\hline Maio & 14,87 & 4,45 & 4,62 & 3,72 & $6,91^{\text {a }}$ & \\
\hline Médias & $8,17^{\mathrm{A}}$ & $3,40^{\mathrm{B}}$ & $3,38^{\mathrm{B}}$ & $3,14^{\mathrm{B}}$ & & \\
\hline $\mathrm{CV}^{*}(\%)$ & \multicolumn{4}{|c|}{25,15} & & \\
\hline
\end{tabular}

* = Coeficiente de variação.

- Médias seguidas de mesma letra, maiúsculas nas linhas e minúsculas nas colunas, não diferem entre si $(\mathrm{P}>0,05)$ pelo teste de Tukey.

Fonte: Elaboração dos autores.

Em todas as épocas de avaliação houve acúmulo sazonal de material morto, contudo, a julgar pela produtividade de matéria seca verde (Tabela 1) observada durante a estação seca nas quatro épocas de utilização, independentemente dos diferimentos, o capim-Marandu parece ter resistido bem ao estresse hídrico no período seco e ao aumento da temperatura, beneficiando-se das precipitações pluviométricas concentradas em fevereiro, março, abril e maio. A dinâmica da distribuição dos componentes nos estratos da pastagem variou ao longo do período de avaliação e durante a seca, onde no início a quantidade de material vivo foi maior e com a idade do capim aumentando o volume de material morto também aumenta. Este comportamento observado está de acordo com Genro et al. (2002), quando avaliaram a densidade de uma pastagem de capim-Marandu. Segundo Van Soest (1994), o envelhecimento da forragem está frequentemente associado ao decréscimo na relação folha/colmo (Tabela 3), o que, de uma maneira geral, também ocorreu com os valores encontrados nesse experimento para relação MV/MM. De acordo com Euclides et al. (2000), a seleção da dieta pelos ruminantes é influenciada pela relação material vivo/material 
morto, sendo, portanto, uma característica de grande relevância na escolha da forrageira para diferimento. Para Brâncio et al. (2003), o consumo máximo do pasto ocorre quando os animais estão em pastagens com alta densidade de folhas acessíveis ao animal, e que caule e/ou material morto podem limitar o consumo, mesmo quando a disponibilidade de matéria seca é alta.

Tabela 3. Relação folha/colmo de Brachiaria brizantha cv. Marandu, em função das épocas de diferimento e utilização, nas condições edafoclimáticas de Parnaíba, Piauí (2011).

\begin{tabular}{|c|c|c|c|c|c|c|}
\hline \multirow{2}{*}{ Épocas de diferimento } & \multicolumn{4}{|c|}{ Épocas de utilização } & \multirow{2}{*}{ Médias } & \multirow{2}{*}{$\mathrm{CV}^{*}(\%)$} \\
\hline & Julho & Agosto & Setembro & Outubro & & \\
\hline Março & 0,47 & 0,32 & 0,32 & 0,29 & $0,35^{\mathrm{b}}$ & \\
\hline Abril & 0,61 & 0,35 & 0,37 & 0,24 & $0,42^{b}$ & 14,06 \\
\hline Maio & 1,08 & 0,64 & 0,65 & 0,61 & $0,74^{\mathrm{a}}$ & \\
\hline Médias & $0,72^{\mathrm{A}}$ & $0,44^{\mathrm{B}}$ & $0,45^{\mathrm{B}}$ & $0,41^{\mathrm{B}}$ & & \\
\hline $\mathrm{CV}^{*}(\%)$ & \multicolumn{4}{|c|}{15,06} & & \\
\hline
\end{tabular}

* = Coeficiente de variação.

- Médias seguidas de mesma letra, maiúsculas nas linhas e minúsculas nas colunas, não diferem entre si $(\mathrm{P}>0,05)$ pelo teste de Tukey.

Fonte: Elaboração dos autores.

A relação folha/colmo (F/C) é um dos principais parâmetros para a alimentação de ruminantes e tem sido tradicionalmente aceita como um índice de qualidade das pastagens. Ademais, sob pastejo, a folha é o maior componente da dieta selecionada pelos animais (SANTOS et al., 2011). Nesse experimento, isoladamente, as épocas de diferimento e utilização do capim-Marandu apresentaram efeito significativo $(\mathrm{P}<0,05)$ para esse parâmetro. $\mathrm{O}$ diferimento em maio e a utilização em julho apresentou a maior relação folha/colmo (Tabela 3), devido ao menor intervalo de crescimento das plantas, quando comparado com os outros meses de utilização, fato também destacado por Steinberg et al. (2012) após avaliar Panicum coloratum em dois períodos de diferimento e três de utilização na região semiárida da Argentina.

Pinto, Gomide e Maestri (1994) sugerem a relação $\mathrm{F} / \mathrm{C}$ igual a 1,0 como limite mínimo para qualidade das forrageiras. Neste experimento, apenas o diferimento em maio com utilização em julho atenderia essa recomendação (Tabela 3).
As épocas de diferimento não apresentaram influências $(\mathrm{P}>0,05)$ sobre os teores de proteína da folha e do colmo (Tabela 4). Isoladamente, foi verificado efeito significativo $(\mathrm{P}<0,05)$ para os teores de proteína bruta das folhas e colmos para as épocas de utilização avaliadas. Quando a pastagem foi utilizada em julho, os teores de proteína das folhas apresentaram-se superiores aos demais meses de utilização. Os teores de proteína dos colmos também se destacaram em julho em relação aos demais (Tabela 4). Este resultado era esperado, pois o mês em questão permaneceu menos tempo sob diferimento e em condições climáticas favoráveis, ademais, apresentaram melhor relação folha/ colmo. Gonçalves et al. (2002) enfatizaram que à medida que a planta amadurece, há um decréscimo no conteúdo celular e, consequentemente, um declínio na porcentagem de proteína bruta tal como observado neste estudo.

A proteína, seguida da energia, é o nutriente mais exigido pelos ruminantes. O nível crítico dos teores de proteína bruta da dieta foi estimado 
em 7\% por Minson (1990), abaixo do qual limita o desenvolvimento dos microrganismos do rúmen, a digestibilidade e o consumo da forragem, resultando em baixo desempenho dos animais. Nesse experimento, apenas as folhas atenderiam esse limite. Declínios significativos na percentagem de proteína bruta, à medida que as plantas forrageiras maturam, foram reportados para diversas gramíneas (CARRILLO et al., 2000;
SCARBROUGH et al., 2002; VENECIANO; FRIGERIO, 2003; EVERS; REDMON; PROVIN, 2004; MÁRQUEZ et al., 2007; FERRI, 2011; ORTEGA-GÓMEZ et al., 2011; OLIVEIRA et al., 2011). Costa, Oliveira e Paulino (1993), observaram diminuições nos teores de proteína bruta de $8,4 \%$ para $7,1 \%$ quando o diferimento foi realizado em fevereiro e abril, respectivamente, para o capim-Marandu.

Tabela 4. Proteína bruta (\%) da folha e colmo de Brachiaria brizantha cv. Marandu, em função das épocas de diferimento e utilização, nas condições edafoclimáticas de Parnaíba, Piauí (2011).

\begin{tabular}{|c|c|c|c|c|c|c|}
\hline \multirow{2}{*}{ Épocas de diferimento } & \multicolumn{4}{|c|}{ Épocas de utilização } & \multirow{2}{*}{ Médias } & \multirow{2}{*}{$\mathrm{CV}^{*}(\%)$} \\
\hline & Julho & Agosto & Setembro & Outubro & & \\
\hline \multicolumn{7}{|c|}{ Folha } \\
\hline Março & 10,71 & 9,30 & 8,09 & 7,52 & 8,91 & \\
\hline Abril & 10,08 & 9,09 & 7,38 & 7,41 & 8,49 & 11,54 \\
\hline Maio & 10,39 & 8,34 & 7,05 & 6,43 & 8,05 & \\
\hline Médias & $10,39^{\mathrm{A}}$ & $8,91^{\mathrm{B}}$ & $7,51^{\mathrm{C}}$ & $7,12^{\mathrm{C}}$ & & \\
\hline $\mathrm{CV}^{*}(\%)$ & & & & & & \\
\hline \multicolumn{7}{|c|}{ Colmo } \\
\hline Março & 3,27 & 2,90 & 3,06 & 3,02 & 3,06 & \\
\hline Abril & 3,32 & 4,12 & 3,22 & 2,82 & 3,37 & 12,2 \\
\hline Maio & 4,53 & 3,32 & 3,09 & 2,86 & 3,45 & \\
\hline Médias & $3,71^{\mathrm{A}}$ & $3,44^{\mathrm{AB}}$ & $3,12^{\mathrm{AB}}$ & $2,90^{\mathrm{B}}$ & & \\
\hline $\mathrm{CV}^{*}(\%)$ & \multicolumn{4}{|c|}{17,43} & & \\
\hline
\end{tabular}

* = Coeficiente de variação.

- Médias seguidas de mesma letra, maiúsculas nas linhas e minúsculas nas colunas, não diferem entre si $(\mathrm{P}>0,05)$ pelo teste de Tukey.

Fonte: Elaboração dos autores.

Os teores de extrato etéreo das folhas do capimMarandu responderam apenas para as épocas de utilização $(\mathrm{P}<0,05)$, ao mesmo tempo em que os colmos apresentaram interação $(\mathrm{P}<0,05)$ entre épocas de diferimento e épocas de utilização (Tabela 5), porém, não ultrapassaram o limite de $6 \%$ de extrato etéreo da dieta a partir do qual se poderia limitar o consumo de matéria seca por ruminantes (SOUZA et al., 2009). Os teores de extrato etéreo encontrados neste trabalho estão próximos aos relatados por Mari (2003), que obteve valores de extrato etéreo em capim-Marandu de 2,7 a $1,9 \%$, respectivamente, aos 15 e 90 dias de idade. Vale enfatizar que em plantas forrageiras os teores de extrato etéreo na matéria seca podem variar até 4\% (CARDOSO et al., 2006). Ademais, quando a planta forrageira amadure ocorre a translocação do extrato etéreo para os grãos, reduzindo seu teor nas folhas e colmos.

A determinação dos teores de cinzas ou matéria mineral fornece uma indicação da concentração dos nutrientes minerais da gramínea. Nesse experimento, os teores de matéria mineral nas folhas apresentaram efeito significativo $(\mathrm{P}<0,05)$, apenas para as épocas 
de utilização, com os menores valores nos meses de setembro e outubro (Tabela 6). Ao mesmo tempo, os colmos do capim-Marandu apresentaram diferenças estatísticas $(\mathrm{P}<0,05)$ para as épocas de diferimento e utilização (Tabela 6). Isoladamente, os menores teores foram registrados com o diferimento em março ou abril e a época de utilização em outubro. Flores et al. (2013) também revelaram reduções nos teores de cinzas do capim-elefante, em função do aumento da idade de utilização.

Tabela 5. Extrato etéreo (\%) da folha e colmo do capim Brachiaria brizantha cv. Marandu, em função das épocas de diferimento e utilização nas condições edafoclimáticas de Parnaíba, Piauí (2011).

\begin{tabular}{|c|c|c|c|c|c|c|}
\hline \multirow{2}{*}{ Épocas de diferimento } & \multicolumn{4}{|c|}{ Épocas de utilização } & \multirow{2}{*}{ Médias } & \multirow{2}{*}{$\mathrm{CV}^{*}(\%)$} \\
\hline & Julho & Agosto & Setembro & Outubro & & \\
\hline \multicolumn{7}{|c|}{ Folha } \\
\hline Março & 2,67 & 2,55 & 2,68 & 2,68 & 2,65 & \\
\hline Abril & 2,48 & 2,54 & 2,87 & 3,04 & 2,73 & 7,06 \\
\hline Maio & 2,60 & 2,74 & 2,73 & 3,00 & 2,77 & \\
\hline Médias & $2,58^{\mathrm{B}}$ & $2,61^{\mathrm{B}}$ & $2,76^{\mathrm{AB}}$ & $2,91^{\mathrm{A}}$ & & \\
\hline $\mathrm{CV}^{*}(\%)$ & & & & & & \\
\hline & & & & \\
\hline Março & $0,44^{\mathrm{Ab}}$ & $0,60^{\mathrm{Aa}}$ & $0,48^{\mathrm{Ab}}$ & $0,34^{\mathrm{Ab}}$ & & \\
\hline Abril & $0,54^{\mathrm{Ab}}$ & $0,69^{\mathrm{Aa}}$ & $0,72^{\mathrm{Aa}}$ & $0,79^{\mathrm{Aa}}$ & & 18,99 \\
\hline Maio & $0,90^{\mathrm{Aa}}$ & $0,80^{\mathrm{Aa}}$ & $0,73^{\text {Аa }}$ & $0,44^{\mathrm{Ab}}$ & & \\
\hline $\mathrm{CV}^{*}(\%)$ & \multicolumn{4}{|c|}{20,32} & & \\
\hline
\end{tabular}

* = Coeficiente de variação.

- Nas folhas, médias seguidas de mesma letra, maiúsculas nas linhas e minúsculas nas colunas, não diferem entre si $(\mathrm{P}>0,05)$ pelo teste de Tukey. Nos colmos, médias seguidas de mesma combinação de letras não diferem entre si $(\mathrm{P}>0,05)$ pelo teste de Tukey.

Fonte: Elaboração dos autores.

Tabela 6. Teores de cinzas (\%) da folha e colmo do capim Brachiaria brizantha cv. Marandu, em função das épocas de diferimento e utilização nas condições edafoclimáticas de Parnaíba, Piauí (2011).

\begin{tabular}{|c|c|c|c|c|c|c|}
\hline \multirow{2}{*}{ Épocas de diferimento } & \multicolumn{4}{|c|}{ Épocas de utilização } & \multirow{2}{*}{ Médias } & \multirow{2}{*}{$\mathrm{CV}^{*}(\%)$} \\
\hline & Julho & Agosto & Setembro & Outubro & & \\
\hline \multicolumn{7}{|c|}{ Folha } \\
\hline Março & 7,81 & 7,39 & 6,27 & 6,05 & 6,88 & \\
\hline Abril & 7,10 & 6,69 & 5,32 & 5,31 & 6,11 & 14,33 \\
\hline Maio & 6,59 & 7,48 & 6,88 & 5,33 & 6,57 & \\
\hline Médias & $7,16^{\mathrm{A}}$ & $7,19^{\mathrm{A}}$ & $6,16^{\mathrm{B}}$ & $5,57^{\mathrm{B}}$ & & \\
\hline CV $(\%)$ & & & & & & \\
\hline \multicolumn{7}{|c|}{ Colmo } \\
\hline Março & 3,44 & 3,12 & 2,59 & 2,32 & $2,87^{\mathrm{b}}$ & \\
\hline Abril & 3,53 & 3,27 & 2,44 & 2,25 & $2,88^{\mathrm{b}}$ & 5,45 \\
\hline Maio & 3,65 & 3,56 & 3,47 & 3,26 & $3,48^{\mathrm{a}}$ & \\
\hline Médias & $3,54^{\mathrm{A}}$ & $3,32 \mathrm{AB}$ & $2,84^{\mathrm{BC}}$ & $2,61^{\mathrm{C}}$ & & \\
\hline CV (\%) & \multicolumn{4}{|c|}{12,15} & & \\
\hline
\end{tabular}

* = Coeficiente de variação.

- Médias seguidas de mesma letra, maiúsculas nas linhas e minúsculas nas colunas, não diferem entre si (P>0,05) pelo teste de Tukey.

Fonte: Elaboração dos autores. 
Além da idade de corte, outra provável explicação para este fato pode ser a redução da precipitação pluviométrica ocorrida no período, que refletiu negativamente na umidade do solo, diminuindo o carregamento de nutrientes para o interior da planta. Contudo, conforme as considerações de Castro et al. (1999), ressalta-se que, com a maturidade das plantas verifica-se, comumente, queda nos teores dos minerais, em decorrência do efeito de sua diluição na matéria seca produzida. Também ocorre redução na relação folha/colmo, aumento de folhas senescentes, diversidade no padrão de absorção dos elementos durante o ciclo dos vegetais, e sua redistribuição entre os vários órgãos das plantas, levando à diminuição da concentração dos minerais na planta.

Nas folhas do capim-Marandu os teores de fibra em detergente neutro (FDN) responderam $(\mathrm{P}<0,05)$ apenas para as épocas de utilização. Nos colmos houve efeito significativo $(\mathrm{P}<0,05)$ para as épocas de diferimento e utilização (Tabela 7), indicando redução na qualidade da forragem com o avanço da idade da planta, fato também relatado por Cedeño et al. (2003) e Magalhães et al. (2009). As maiores mudanças que afetam a composição química das forrageiras são aquelas que acompanham sua idade (CARVALHO; PIRES, 2008). À medida que a planta amadurece, a produção dos componentes potencialmente digestíveis tende a decrescer, e a fibra, a aumentar, assim com o avanço do estádio de maturação da forrageira, ocorre senescência natural, contribuindo para maior lignificação (BUENO et al., 2000).

Ressalta-se que a FDN é o componente da forragem mais consistentemente associada ao consumo (ALLEN, 2000; BENETT et al., 2008), assim, menores teores de FDN permitem um consumo de forragem de melhor qualidade pelo animal. Nesse experimento, considerando-se os teores de FDN da folha, independentemente das épocas de diferimento, as melhores épocas de utilização foram julho e agosto.

Tabela 7. Teores (\%) de fibra em detergente neutro (FDN) na folha e colmo de Brachiaria brizantha cv. Marandu, em função das épocas de diferimento e utilização, nas condições edafoclimáticas de Parnaíba, Piauí (2011).

\begin{tabular}{|c|c|c|c|c|c|c|}
\hline \multirow{2}{*}{ Épocas de diferimento } & \multicolumn{4}{|c|}{ Épocas de utilização } & \multirow{2}{*}{ Médias } & \multirow{2}{*}{$\mathrm{CV}^{*}(\%)$} \\
\hline & Julho & Agosto & Setembro & Outubro & & \\
\hline \multicolumn{7}{|c|}{ Folha } \\
\hline Março & 61,15 & 61,46 & 62,83 & 63,28 & 62,18 & \\
\hline Abril & 60,36 & 60,55 & 61,91 & 62,45 & 61,32 & 2,99 \\
\hline Maio & 59,73 & 60,33 & 61,80 & 61,73 & 60,90 & \\
\hline Médias & $60,42^{\mathrm{C}}$ & $60,77^{\mathrm{BC}}$ & $62,18^{\mathrm{AB}}$ & $62,48^{\mathrm{A}}$ & & \\
\hline $\mathrm{CV}^{*}(\%)$ & & & & & & \\
\hline \multicolumn{7}{|c|}{$\begin{array}{l}1,89 \\
\text { Colmo }\end{array}$} \\
\hline Março & 70,03 & 72,28 & 73,98 & 75,07 & $72,84^{\mathrm{a}}$ & \\
\hline Abril & 68,25 & 70,27 & 71,15 & 71,95 & $70,40^{\mathrm{b}}$ & 1,85 \\
\hline Maio & 66,31 & 28,13 & 71,16 & 72,01 & $69,41^{\mathrm{b}}$ & \\
\hline Médias & $68,20^{\mathrm{C}}$ & $70,23^{\text {B }}$ & $72,10^{\mathrm{AB}}$ & $73,01^{\mathrm{A}}$ & & \\
\hline $\mathrm{CV}^{*}(\%)$ & \multicolumn{4}{|c|}{2,00} & & \\
\hline
\end{tabular}

* = Coeficiente de variação.

- Médias seguidas de mesma letra, maiúsculas nas linhas e minúsculas nas colunas, não diferem entre si (P>0,05) pelo teste de Tukey.

Fonte: Elaboração dos autores. 
Os teores de fibra em detergente ácido (FDA) das folhas e colmos responderam apenas aos efeitos das épocas de utilização (Tabela 8), provavelmente como decorrência do aumento da proporção de constituintes da parede celular com a idade de corte. Os teores de FDA têm relação com os teores de lignina dos alimentos, que determinam a sua digestibilidade, pois quanto menor o teor de FDA, menor será o teor de lignina e, consequentemente, melhor a digestibilidade do alimento. Desta forma, nesse experimento, em razão dos teores de FDA da folha e do colmo, independentemente do diferimento, a melhor época de utilização foi julho.

Tabela 8. Teores (\%) de fibra em detergente ácido (FDA) na folha e colmo de Brachiaria brizantha cv. Marandu, em função das épocas de diferimento e utilização, nas condições edafoclimáticas de Parnaíba, Piauí (2011).

\begin{tabular}{|c|c|c|c|c|c|c|}
\hline \multirow{2}{*}{ Épocas de diferimento } & \multicolumn{4}{|c|}{ Épocas de utilização } & \multirow{2}{*}{ Médias } & \multirow{2}{*}{$\mathrm{CV}^{*}(\%)$} \\
\hline & Julho & Agosto & Setembro & Outubro & & \\
\hline \multicolumn{7}{|c|}{ Folha } \\
\hline Março & 39,55 & 40,12 & 43,96 & 41,11 & 46,18 & \\
\hline Abril & 38,26 & 42,98 & 47,34 & 40,73 & 45,21 & 3,17 \\
\hline Maio & 42,83 & 44,41 & 41,99 & 42,60 & 44,47 & \\
\hline Médias & $42,66^{\mathrm{B}}$ & $43,94^{\mathrm{B}}$ & $47,03^{\mathrm{A}}$ & $47,51^{\mathrm{A}}$ & & \\
\hline \multirow{2}{*}{\multicolumn{7}{|c|}{$\begin{array}{l}4,90 \\
\text { Colmo }\end{array}$}} \\
\hline & & & & & & \\
\hline Março & 48,40 & 48,99 & 50,44 & 50,41 & 49,59 & \\
\hline Abril & 46,46 & 48,45 & 49,17 & 49,76 & 48,46 & 1,88 \\
\hline Maio & 45,62 & 48,15 & 48,89 & 49,14 & 47,95 & \\
\hline Médias & $46,83^{\text {в }}$ & $48,53 \mathrm{AB}$ & $49,50^{\mathrm{AB}}$ & $49,80^{\mathrm{A}}$ & & \\
\hline $\mathrm{CV}^{*}(\%)$ & \multicolumn{4}{|c|}{4,17} & & \\
\hline
\end{tabular}

* = Coeficiente de variação.

- Médias seguidas de mesma letra, maiúsculas nas linhas e minúsculas nas colunas, não diferem entre si $(\mathrm{P}>0,05)$ pelo teste de Tukey.

Fonte: Elaboração dos autores.

Reis (2000) observou resultado semelhante, ou seja, correlação positiva para o teor de FDA e avanço na maturidade avaliando cinco espécies forrageiras, dentre elas o capim-Marandu, cortadas a cada 30 dias, por um ano. Tessema e Alemayehu (2010), avaliando a qualidade do capim-elefante cv. Napier, também verificaram aumento nos teores de FDA nas frequências de corte de 60 dias, 36,0\% de FDA; 90 dias, 39,8\% de FDA e 120 dias com 41,0\% de FDA.

\section{Conclusões}

Nas condições ecológicas dos Tabuleiros Costeiros do Piauí, o diferimento de pastagens de
Brachiaria brizantha cv. Marandu durante o período chuvoso, de modo a acumular forragem para a suplementação dos rebanhos durante o período seco, é uma prática tecnicamente viável.

O diferimento em março ou abril, com utilizações em julho a outubro, respectivamente, proporciona maiores produções de matéria seca verde, contudo, o diferimento em maio e utilização em julho apresentou melhor relação material vivo/ material morto.

A forragem com melhor relação folha/colmo e maiores teores de proteína bruta e cinzas, e menores teores de fibra em detergente neutro e fibra em 
detergente ácido, foram verificados com utilizações nos meses de julho e agosto, independentemente da época de diferimento.

Visando conciliar rendimento e composição química da forragem do capim-Marandu, recomenda-se o diferimento em abril ou maio para utilização em julho ou agosto, respectivamente.

\section{Referências}

ABREU, J. B. R.; DEMENICIS, B. B.; SATYRO, R. H.; SIMONE, G. A. de; TEIXEIRA, M. C.; CHAMBELA NETO, A.; SANT'ANA, N. de F.; MENEZES, J. B. de O. X. de. Avaliação da disponibilidade de matéria seca e produção de resíduos vegetais (serrapilheira) em função de diferentes épocas de vedação em pastagem de capim-braquiária (Brachiaria decumbens). Revista Universidade Rural. Série Ciências da Vida, Seropédica, v. 24, n. 2, p. 127-134, 2004.

ALLEN, M. S. Effects of diet on short-term regulation of feed intake by lactating dairy cattle. Journal of Dairy Science, Champaign, v. 83, n. 7, p. 1598-1624, 2000.

BARBOSA, C. L.; MONKS, P. L.; CENTENO, G. A. Produção e qualidade da forragem do capim-elefante (Pennisetum purpureum Schum. ) cv. Vruckwona submetido a diferentes épocas de diferimento e cortes. Ciência Rural, Santa Maria, v. 25, n. 1, p. 115-119, 1995.

BENDAHAN, A. B.; COSTA, N. de L.; BRAGA, R. M.; MATTOS, P. S. R.; MEDEIROS, R. D.; FERREIRA, G. B. Potencial de utilização da cana-de-açúcar para alimentação animal nos cerrados de Roraima. Amazônia: ciência e desenvolvimento, Belém, v. 4, n. 8, p. 175-182, 2009.

BENETT, C. G. S.; BUZETTI, S.; SILVA, K. S.; BERGAMASCHINE, A. F.; FABRICIO, J. A. Produtividade e composição bromatológica do capimMarandu a fontes e doses de nitrogênio. Ciência e Agrotecnologia, Lavras, v. 32, n. 5, p. 1629-1636, 2008.

BERCHIELLI, T. T.; SADER, A. P. de O.; TONANI, F. L.; PAZIANI, S. de F.; ANDRADE, P. de. Use of the Ankom system to determine neutral detergent fiber and acid detergent fiber with different filter bags, and sample amounts. Revista Brasileira de Zootecnia, Viçosa, MG, v. 30, n. 5, p. 1572-1578, 2001.

BOTREL, M. de A.; ALVIM, M. J.; XAVIER, D. F. Avaliação de gramíneas forrageiras na Região Sul de Minas Gerais. Pesquisa Agropecuária Brasileira, Brasília, v. 34, n. 4, p. 683-689, 1999.
BRÂNCIO, P. A.; EUCLIDES, V. P. B.; NASCIMENTO JÚNIOR, D. do; FONSECA, D. M. da; ALMEIDA, R. G.; MACEDO, M. C. M.; BARBOSA, R. A. Avaliação de três cultivares de Panicum maximum Jacq. sob pastejo: disponibilidade de forragem, altura do resíduo pós-pastejo e participação de folhas, colmos e material morto. Revista Brasileira de Zootecnia, Viçosa, MG, v. 32, n. 1, p. 55-63, 2003.

BUENO, M. F.; MATTOS, H. B.; COSTA M. N. X.; PIEDADE, S. M. de S.; LEITE, W. B. de O. Épocas de vedação e de uso no capim-Marandu. I. Produção de matéria seca e valor nutritivo. Boletim de Indústria Animal, Nova Odessa, v. 57, n. 1, p. 1-9, 2000.

BURNS, J. C.; WEDIN, W. F. Yield and chemical composition of sudangrass and forage sorghum under three systems of summer management for late fall in situ utilization. Agronomy Journal, Madison, v. 56, n. 5, p. 457-460, 1964.

CANTO, M. W. do; JOBIM, C. C.; CECATO, U.; CASTRO, C. R. de C.; HOESCHL, A. R.; GALBEIRO, S.; CONEGLIAN, S. M.; PERES, R. S. M.; MOREIRA, H. L. M. Acúmulo de forragem e perfilhamento em capim Tanzânia, Panicum maximum Jacq., diferido após pastejo em diferentes alturas. Acta Scientiarum. Animal Sciences, Maringá, v. 24, n. 4, p. 1087-1092, 2002.

CARDOSO, E. da C.; BRAGA, E.; CAMARÃO, A. P.; MORENO, W. C.; SOUZA, S. S.; MOUTINHO, J. Teores de proteína bruta, extrato etéreo e minerais de gramíneas nativas Paspalum repens e Paspalum fasciculatum de ecossistemas de várzea do Baixo Amazonas, Pará, Brasil. Pasturas Tropicales, Cali, v. 28, n. 1, p. 67-71, 2006.

CARRILlO, V.; RODRÍGUEZ, R.; MANRÍQUE, U.; VÁSQUEZ, D.; RIVAS, E.; FARIÑAS, J. Efecto de fertilización nitrogenada, edad y epoca de corte sobre el valor nutritivo del pasto Andropogon gayanus. Zootecnia Tropical, Maracay, v. 18, n. 2, p. 237-254, 2000.

CARVAlHO, G. G. P.; PIRES, A. J. V. Organização dos tecidos de plantas forrageiras e suas implicações para os ruminantes. Archivos de Zootecnia, Córdoba, v. 57R, p. 13-28, 2008.

CASTRO, F. G. F.; HADDAD, C. M.; VIEIRA, A. C.; VENDRAMINI, J. M. B.; HEISECKE, O. R. P. Época de corte, produção, composição químico-bromatológica e digestibilidade da matéria seca da grama estrela Florico. Scientia Agricola, Piracicaba, v. 56, n. 1, p. 225-233, 1999.

CEDEÑO, J. A. G.; ROCHA, G. P.; PINTO, J. C.; MUNIZ, J. A.; GOMIDE, E. M. Efeito da idade de corte na performance de três forrageiras do gênero Cynodon. Ciência e Agrotecnologia, Lavras, v. 27, n. 2, p. 462470, 2003. 
COSTA, N. de L. Manejo de pastagens de Brachiaria brizantha cv. Marandu em Rondônia. Porto Velho: Embrapa Rondônia, 2001. 3 p. (Recomendações técnicas, 33).

COSTA, N. de L.; MAGALHÃES, J. A.; TOWNSEND, C. R.; PEREIRA, R. G. de A.; OLIVEIRA, J. R. da C. Considerações sobre o manejo de pastagens na Amazônia Ocidental. Revista CFMV, Brasília, v. 13, n. 40, p. 37-55, 2007.

COSTA, N. de L.; OLIVEIRA, J. R. da C. Épocas de vedação e utilização de Andropogon gayanus cv. Planaltina em Rondônia. Lavoura Arrozeira, Porto Alegre, v. 45, n. 402, p. 15-16, 1992.

COSTA, N. de L.; TOWNSEND, C. R.; MAGALHÃES, J. A.; PAULINO, V. T. Efeito do diferimento sobre a produção de forragem e composição química de Brachiaria brizantha cv. Xaraés. Pubvet, Londrina, v. 4, n. 10, p.1-11, 2010.

COSTA, N. de L.; OLIVEIRA, J. R. C.; PAULINO, V. $\mathrm{T}$. Efeito do diferimento sobre o rendimento de forragem e composição química de Brachiaria brizantha cv. Marandu em Rondônia. Revista da Sociedade Brasileira de Zootecnia, Viçosa, MG, v. 22, n. 1, p. 495-501, 1993.

EUCLIDES, V. P. B.; CARDOSO, E. G.; MACEDO, M. C. M.; OLIVEIRA, M. P. Consumo voluntário de Brachiaria decumbens cv. Basilisk e Brachiaria brizantha cv. Marandu sob pastejo. Revista da Sociedade Brasileira de Zootecnia, Viçosa, MG, v. 29, n. 6, p. 22002208, 2000.

EUCLIDES, V. P. B.; FLORES, R. S.; MEDEIROS, R. N. de; OLIVEIRA, M. P. Diferimento de pastos de braquiária cultivares Basilisk e Marandu, na região do Cerrado. Pesquisa Agropecuária Brasileira, Brasília, v. 42, n. 2, p. 273-280, 2007.

EUClideS, V. P. B.; VALlE, C. B.; SILVA, J. M. Avaliação de forrageiras tropicais manejadas para produção de feno-em-pé. Pesquisa Agropecuária Brasileira, Brasília, v. 25, n. 3, p. 393-407, 1990.

EVERS, G. W.; REDMON, L. A.; PROVIN, T. L. Comparison of bermudagrass, bahiagrass, and kikuyugrass as a standing hay crop. Crop Science, Madison, v. 44, n. 4, p. 1370-1378, 2004.

FERRI, C. M. The seasonal and inter-annual patterns of biomass accumulation and crude protein in kleingrass (Panicum coloratum) in the semiarid pampean region of Argentina. Ciencia e Investigación Agropecuaria, Santiago, v. 38, n. 2, p. 191-198, 2011.

FLORES, R. A.; URQUIAGA, S.; ALVES, B. J. R.; COLLIER, L. S.; ZANETTI, J. B.; PRADO, R. de M.
Nitrogênio e idade de corte na qualidade da biomassa de capim-elefante para fins agroenergéticos cultivado em Latossolo. Semina: Ciências Agrárias, Londrina, v. 34, n. 1, p. 127-136, 2013.

FRANÇA, L. V. Viabilidade de produção de sementes de Brachiaria brizantha Stapf cv. Marandu em Cabeceiras GO. Brasília: UPIS, 2005. 35 p. (Boletim técnico).

GENRO, T. C. M.; THIAGO, L. R. L. S.; EUCLIDES, V. B. P.; PRATES, E. R.; MELlO, R. O. Densidade de forragem nos estratos verticais de uma pastagem de B. brizantha $\mathrm{cv}$. Marandu. In: REUNIÃO ANUAL DA SOCIEDADE BRASILEIRA DE ZOOTECNIA, 39., 2002, Recife. Anais... Recife: SBZ, 2002. 3 p. CD-ROM.

GERDES, L.; WERNER, J. C.; COLOZZA, M. T.; CARVALHO, D. D.; SCHAMMAS, E. A. Avaliação de características agronômicas e morfológicas das gramíneas forrageiras Marandu, Setária e Tanzânia aos 35 dias de crescimento nas estações do ano. Revista Brasileira de Zootecnia, Viçosa, v. 29, n. 4, p. 947-954, 2000.

GOMES, V. M. Disponibilidade e valor nutritivo de braquiária vedada para uso na região semiárida de Minas Gerais. 2003. Dissertação (Mestrado em Zootecnia) - Universidade Federal de Lavras, Lavras.

GONÇALVES, G. D.; SANTOS, G. T.; CECATO, U.; JOBIM, C. C.; DAMASCENO, J. C.; FARIA, K. P. Produção e valor nutritivo de gramíneas do gênero Cynodon em diferentes idades ao corte durante o ano. Acta Scientiarum, Maringá, v. 14, n. 2, p. 1163-1174, 2002.

GUERRA FILHO, P. A. Sensibilidade da Brachiaria brizantha cv. Marandu ao excesso de água no solo. 2012. Dissertação (Mestrado em Irrigação e Drenagem) - Escola Superior de Agricultura Luiz de Queiroz. Universidade de São Paulo, Piracicaba.

HEINRICHS, R.; SOARES FILHO, C. V.; CRUCCIOLI, C.; FIGUEIREDO, P. A. M. de; FRUCHI, V. M.; KODEL, F. J.; RODRIGUES, T. A. Doses and sources of nitrogen fertilizer and their effects on soil chemical properties and forage yield of Brachiaria brizantha cv. Xaraés. Semina: Agrárias, Londrina, v. 33, n. 5, p. 1747-1756, 2012.

LALMAN, D. L.; TALIAFERRO, C. M.; EPPLIN, F. M.; JOHNSON, C. R.; WHEELER, J. S. Review: grazing stockpiled bermudagrass as an alternative to feeding harvested forage. Journal of Animal Science, Madison, v. 79, p. 1-8, 2000. Supplement 1.

LEITE, G. G.; COSTA, N. de L.; GOMES, A. C. Efeito de épocas de diferimento sobre a produção e qualidade da forragem de gramíneas na região dos Cerrados do Brasil. Pasturas Tropicales, Cali, v. 20, n. 1, p. 15-22, 1998. 
MAGALHÃES, J. A.; CARNEIRO, M. S. de S.; ANDRADE, A. C.; PEREIRA, E. S.; SOUTO, J. S.; PINTO, M. S. de C.; RODRIGUES, B. H. N.; COSTA, N. de L.; MOCHEL FILHO, W. J. E. Eficiência do nitrogênio, produtividade e composição do capimandropogon sob irrigação e adubação. Archivos de Zootecnia, Córdoba, v. 61, n. 236, p. 577-588, 2012.

MAGAlHÃES, J. A.; RODRIGUES, B. H. N.; CARNEIRO, M. S. S.; ANDRADE, A. C.; COSTA, N. de L.; PINTO, M. S. C.; ERICEIRA, W. J. Influencia da adubação nitrogenada e idade de corte sobre os teores de proteína bruta e fibra em detergente neutro de três cultivares de capim-elefante. Revista Electrónica de Veterinária, Málaga, v. 10, n. 4, p. 1695-1702, 2009.

MARI, L. J. Intervalo entre cortes em capim-Marandu (Brachiaria brizantha (Hochts. ex A. Rich.) Stapf cv. Marandu): produção, valor nutritivo e perdas associadas à fermentação da silagem. 2003. Dissertação (Mestrado em Agronomia) - Escola Superior de Agricultura Luiz de Queiroz, Piracicaba.

MÁRQUEZ, F.; SÁNCHEZ, J.; URBANO, D.; DÁVILA, C. Evaluación de corte y tipos de fertilización sobre tres genotipos de pasto elefante (Pennisetum purpureum). Rendimiento y contenido de proteína. Zootecnia Tropical, Luz, v. 25, n. 4, p. 253-259, 2007.

MELLO, R.; NÖRNBERG, J. L.; ROCHA, M. G. Potencial produtivo e qualitativo de híbridos de milho, sorgo e girassol para ensilagem. Revista Brasileira de Agrociência, Pelotas, v. 10, n. 1, p. 87-95, 2004.

MELO, F. B.; CAVALCANTE, A. C.; ANDRADE JÚNIOR, A. S.; BASTOS, E. A. Levantamento detalhado dos solos da área da Embrapa Meio-Norte/UEP de Parnaiba. Teresina: Embrapa Meio-Norte, 2004. 26 p.(Documentos 89).

MINSON, D. J. Forage in ruminant nutrition. San Diego: Academic Press, 1990. 483 p.

MOREIRA, G. R.; SALIBA, E. O. S.; GONÇALVES, L. C.; MAURÍCIO, R. M.; SOUSA, L. F.; RODRIGUEZ, N. M.; LANA, A. M. Q. Avaliação nutricional de fenos produzidos com Andropogon gayanus cv. Planaltina. Arquivo Brasileiro de Medicina Veterinária e Zootecnia, Belo Horizonte, v. 65, n. 3, p. 865-873, 2013.

NIE, Z.; ZOLLINGER, R. Impact of deferred grazing and fertilizer on plant population density, ground cover and soil moisture of native pastures in steep hill country of southern Australia. Grass and Forage Science, Oxford, v. 67 , n. 2, p. 231-242, 2012.

OLIVEIRA, M. A.; PEREIRA, O. G.; RIBEIRO, K. G.; SANTOS, M. E. R.; CHIZZOTTI, F. H. M.; CECON, P. R. Produção e valor nutritivo do capim-coastcross sob doses de nitrogênio e idades de rebrotação. Arquivo Brasileiro de Medicina Veterinária e Zootecnia, Belo Horizonte, v. 63, n. 4, p. 694-703, 2011.

OLIVEIRA, Y.; MACHADO, R.; POZO, P. P. del. Características botánicas y agronómicas de especies forrajeras importantes del género Brachiaria. Pastos y Forrajes, Perico, v. 29, n. 1, p. 5-28, 2006.

ORTEGA-GÓMEZ, R.; CASTILLO-GALLEGOS, E.; JARILLO-RODRÍGUEZ, J.; ESCOBARHERNÁNDEZ, R.; OCAÑA-ZAVALETA, E.; VALLES de LA MORA, B. Nutritive quality of ten grasses during the rainy season in a hot-humid climate and ultisol soil. Tropical and Subtropical Agroecosystems, Mérida, v. 13, n. 3, p. 481-491, 2011.

PINTO, J. C.; GOMIDE, J. A.; MAESTRI, M. Produção de matéria seca e relação folha/caule de gramíneas forrageiras tropicais, cultivadas em vasos, com duas doses de nitrogênio. Revista Brasileira de Zootecnia, Viçosa, MG, v. 23, n. 3, p. 313-326, 1994.

REIS, S. T. dos. Valor nutricional de gramineas tropicais em diferentes idades de corte. 2000. Dissertação (Mestrado em Zootecnia) - Universidade Federal de Lavras, Lavras.

RIBEIRO, J. L.; NUSSIO, L. G.; MOURÃO, G. B.; MARI, L. J.; ZOPOLLATTO, M.; PAZIANI, S. F. Valor nutritivo de silagens de capim-Marandu submetidas aos efeitos de umidade, inoculação bacteriana e estação do ano. Revista Brasileira de Zootecnia, Viçosa, MG, v. 37, n. 7, p. 1176-1184, 2008.

SANTOS FILHO, L. F. Seed production: perspective from the Brazilian private sector. In: MILES, J. W.; MAASS, B. L.; VALLE, C. B. (Ed.). Brachiaria: biology, agronomy and improvement. Cali: CIAT, 1996. p. 141-146.

SANTOS, M. E. R.; FONSECA, D. M.; BALBINO, E. M.; MONNERAT, J. P. I. S.; SILVA, S. P. Capim braquiária diferido e adubado com nitrogênio: produção e características da forragem. Revista Brasileira de Zootecnia, Viçosa, v. 38, n. 4, p. 650-656, 2009.

SANTOS, M. E. R.; FONSECA, D. M.; MAGALHAES, M. A.; SILVA, S. P.; CASAGRANDE, D. R.; BALBINO, E. M.; GOMES, V. M. Estrutura e valor nutritivo do pasto diferido de Brachiaria decumbens cv. Basilisk durante o período de pastejo. Revista Brasileira de Agropecuária Sustentável, Mossoró, v. 1, n. 1, p. 112-122, 2011.

SCARBROUGH, D. A.; COBLENTZ, W. K.; COFFEY, K. P.; TURNER, J. E.; DAVIS, G. V.; KELLOGG, D. W.; HELLWIG, D. H. Effects of summer management and fall harvest date on the in situ degradation of nitrogen in stockpiled bermudagrass. Animal Feed Science and Technology, Gainesville, v. 96, n. 3, p. 119-133, 2002. 
SCHUNKE, R. M. Alternativas de manejo de pastagens para melhor aproveitamento do nitrogênio de solo. Campo Grande: Embrapa Gado de Corte, 2001. 26 p. (Documentos, 111).

SERAFIM, R. S.; GALBIATTI, J. A. Efecto de la aplicación de la agua residual porcina en el pasto Brachiaria brizantha cv. Marandu. Revista Colombiana de Ciencia Animal, Sincelejo, v. 4, n. 1, p. 185-203, 2012.

SILVA, F. de A. S. E.; AZEVEDO, C. A. V. de. Versão do programa computacional Assistat para o sistema operacional Windows. Revista Brasileira de Produtos Agroindustriais, Campina Grande, v. 4, n. 1, p. 71-78, 2002.

SILVA, P. T.; QUEIROZ, A. C. Análise de alimentos: métodos químicos e biológicos. 3. ed. Viçosa: UFV, 2002. $235 \mathrm{p}$.

SOUZA, A. R. D. L.; MEDEIROS, S. R.; MORAIS, M. G.; OSHIRO, M. M.; TORRES JÚNIOR, R. A. A. Dieta com alto teor de gordura e desempenho de tourinhos de grupos genéticos diferentes em confinamento. Pesquisa Agropecuária Brasileira, Brasília, v. 44, n. 7, p. 746-753, 2009.
STEINBERG, M. R.; VALDÉZ, H. A.; CORAGLIO, J. C.; VIEYRA, C. A.; MINUZZI, P. A. Producción y calidad del forraje diferido de Panicum coloratum L. en dos periodos de diferimiento y tres momentos de defoliación. Agriscientia, Córdoba, v. 29, n. 1, p. 25-30, 2012.

TAYLOR, T. H.; TEMPLETON, W. C. Stockpiling kentucky bluegrass and tall fescue forage for winter pasturage. Agronomy Journal, Madison, v. 68, n. 2, p. 235-239, 1976.

TESSEMA, Z. K.; ALEMAYEHU, M. Management of napier grass (Pennisetum Purpureum (L.) Schumach) for high yield and nutritional quality in Ethiopia: A Review. Ethiopian Journal of Animal Production, Addis Ababa, v. 10, n. 1, p. 73-94, 2010.

VAN SOEST, P. J. Nutritional ecology of the ruminant. New York: Cornell University Press, 1994. 476 p.

VENECIANO, J. H.; FRIGERIO, K. L. Efecto de la defoliación de primavera-verano sobre los rendimientos, composición de la materia seca y contenido proteico del material diferido de gramíneas megatérmicas. Revista de Investigaciones Agropecuarias, San Luis, v. 32, n. 1, p. 5-15, 2003. 